\title{
Formation and Maintenance of a Polynya in the Weddell Sea
}

\author{
RALPH TIMMERMANN \\ Alfred-Wegener-Institut für Polar- und Meeresforschung, Bremerhaven, Germany \\ PETER LEMKE \\ Institut für Meereskunde an der Universität Kiel, Kiel, Germany \\ CHRISTOPH KOTTMEIER \\ Institut für Meteorologie und Klimaforschung, Universität Karlsruhe, Karlsruhe, Germany
}

(Manuscript received 5 May 1997, in final form 6 July 1998)

\section{ABSTRACT}

\begin{abstract}
A dynamic-thermodynamic sea ice-mixed layer model for the Weddell Sea is complemented by a simple, diagnostic model to account for local sea ice-atmosphere interaction. To consider the atmospheric influence on the oceanic mixed layer, the pycnocline upwelling velocity is calculated using the theory of Ekman pumping. In several experiments, formation and conservation of a polynya in the Weddell Sea are investigated. Intrusion of heat into the lower atmosphere above the polynya area is assumed to cause a thermal perturbation and a cyclonic thermal wind field. Superposed with daily ECMWF surface winds, this modified atmospheric forcing field intensifies oceanic upwelling and induces divergent ice drift. Simulation results indicate that in case of a weak atmospheric cross-polynya flow the formation of a thermal wind field can significantly extend the lifetime of a large polynya. The repeated occurrence of the Weddell polynya in the years 1974-76 thus appears to be an effect of feedback mechanisms between sea ice, atmosphere, and oceanic mixed layer.
\end{abstract}

\section{Introduction}

During the Southern Hemisphere winter up to 20 million square kilometers of the Antarctic ocean are ice covered. Scattered patches of open water within the sea ice region consist of narrow leads of length 1-10 km and wide openings called polynyas. Although they make up only a few percent of the ice-covered area, leads and polynyas in the winter pack ice are important for a wide range of physical and biological processes. Here, the relatively warm water at freezing temperature is in contact with the cold air above, thus causing large upward turbulent fluxes of heat and water vapor.

Coastal polynyas are a few hundred meters to 100 $\mathrm{km}$ wide and can be explained by prevailing winds and ocean currents at the margins of the Antarctic continent (Kottmeier and Engelbart 1992). In the Weddell Sea, they contribute significantly to the formation of deep and bottom water, which is the major source of the bottom water of the World Ocean (Fahrbach et al. 1995).

Corresponding authors address: Ralph Timmermann, Alfred-Wegener-Inst. for Polar and Marine Research, Am Handelshafen 12, D27570 Bremerhaven, Germany.

E-mail: rtimmerm@awi-bremerhaven.de
Offshore polynyas are far less frequent. The most striking event was observed in the Weddell Sea for the entire winters of 1974-76 and is called "Weddell polynya." Within an area of about $300000 \mathrm{~km}^{2}$ between $64^{\circ}$ and $69^{\circ} \mathrm{S}$ near the Greenwich meridian, the ice concentration did not exceed $15 \%$, while the surrounding area was nearly completely ice covered. According to the analysis of remote sensing data collected by the Electrically Scanning Microwave Radiometer (ESMR), the polynya did not emerge from an already existing ice cover; the ice cover rather grew around the polynya, finally creating a secluded open water area (Zwally et al. 1981).

Different explanations for the occurrence of such an extended and long-lived polynya were given. The simplest mechanism that might cause the formation of a large area of open water would be the export of ice due to a divergent wind field. However, the rate of ice export required to maintain nearly ice-free conditions in the polynya area would be of the order of meters per second. This would require wind speeds averaging over $50 \mathrm{~m}$ $\mathrm{s}^{-1}$, which is clearly too large to be reasonable (Martinson et al. 1981).

From 1974 to 1976 , the polynya shifted westward with a mean velocity of $1 \mathrm{~cm} \mathrm{~s}^{-1}$, consistent with the 
mean ocean current (Carsey 1980). From this point, the phenomenon appears to be related to oceanic processes. Comparison of water temperatures within a depth of 200-2700 m between the years 1973 and 1977 shows substantial cooling after the polynya's occurrence. Gordon (1982) explained this by extensive heat loss to the atmosphere, connected with low stability of the water column and deep convection.

Martinson et al. (1981) proposed that when surface cooling and ice formation reduce the temperature and increase the salinity of a shallow mixed layer, static instability with intense vertical mixing can occur. The upwelled warm, salty deep water can supply enough heat to melt the ice or prohibit its formation. To induce a shallow mixed layer, Martinson et al. (1981) suggested that upwelling may raise the pycnocline until convection can occur. Actually, Gordon and Huber (1984) detected large warm subsurface eddies that traveled from the east into the Weddell Sea. These warm water cells lifted the mixed layer base significantly and increased the pycnocline temperature, leading to more intense entrainment of warm and salty water.

Using a one-dimensional, purely thermodynamic, sea ice-mixed layer model, Lemke (1987) indicated that both a divergent drift of sea ice and the pycnocline upwelling proposed by Martinson et al. can induce the formation of a polynya in three subsequent years:

- A divergent ice drift reduces the mean ice thickness and the ice concentration during the season of sea ice formation. This leads to a higher freezing rate and thus to increased brine rejection.

- Increased upwelling leads to enhanced entrainment of warm, salty deep water into the mixed layer. While heat is lost to the atmosphere, salinity of the mixed layer is preserved (if the effects of diffusion and advection are neglected).

In both cases, increased density of the mixed layer induces deep convection with entrainment heat fluxes of the order of $150 \mathrm{~W} \mathrm{~m}^{-2}$ (Lemke 1987). To reduce the formation of sea ice significantly, it is essential that during the period of increased upwelling the ocean is not yet ice covered. In case of an existing ice cover, melting of sea ice due to entrained heat creates a freshwater flux that stabilizes the upper ocean and inhibits convection.

In a similar simulation using a dynamic-thermodynamic sea ice-mixed layer model (Lemke et al. 1990) the system's response was limited to the first winter. Apparently, advection of sea ice into the ice free area and subsequent melting (i.e., stabilization of the water column) reduces the lifetime of a polynya significantly. In order to maintain a polynya over a longer period (a few years) two prerequisites seem to be necessary:

1) a sufficiently weak oceanic stratification and

2) no inflow of ice into the polynya.

This paper aims to address the second point through

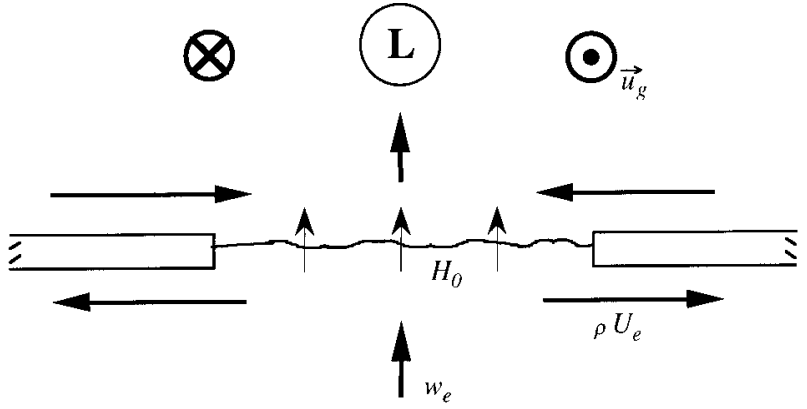

FIG. 1. Section through a secondary low pressure system over a Southern Hemisphere polynya, including the geostrophic wind $\mathbf{u}_{g}$, the Ekman transport $U_{e}$ in the oceanic and the atmospheric boundary layer, and the resulting vertical velocities $w_{e}$.

examination of the interactions between sea ice, the oceanic mixed layer, and lower atmosphere, which can explain the formation and conservation of an open ocean polynya similar to the $1974-76$ observations. As already mentioned, the upward heat fluxes over a polynya far exceed the values over a solid ice cover. Assuming that this causes local warming of the lower atmosphere, a low pressure system associated with cyclonic thermal wind will be forced to develop. This will have two effects on sea ice conditions (Fig. 1):

1) The surface wind stress will induce a divergent ice drift.

2) The curl of the surface wind stress will (according to the theory of Ekman pumping) enhance the oceanic upwelling velocity.

Through the export of ice out of the polynya, this local wind system may be able to maintain itself — as long as the surrounding area is ice covered and the large-scale pressure gradients are relatively small.

To focus on this item, a state-of-the-art sea ice model is coupled to a diagnostic model of the thermal wind system, which is introduced in the following section. Results of the coupled simulations are presented and consequences for the maintenance of the polynya are discussed.

\section{Model description}

\section{a. Sea ice-mixed layer model}

The sea ice dynamics is based on the dynamic-thermodynamic sea ice model presented by Hibler (1979). Thermodynamic ice growth rates are derived from a surface energy balance (Parkinson and Washington 1979) using the Semtner (1976) zero-layer approach for heat conduction. The incoming longwave and shortwave radiation fluxes are treated with standard formulations based on Idso and Jackson (1969) and Zillmann (1972). A prognostic snow layer (Owens and Lemke 1990) ac- 


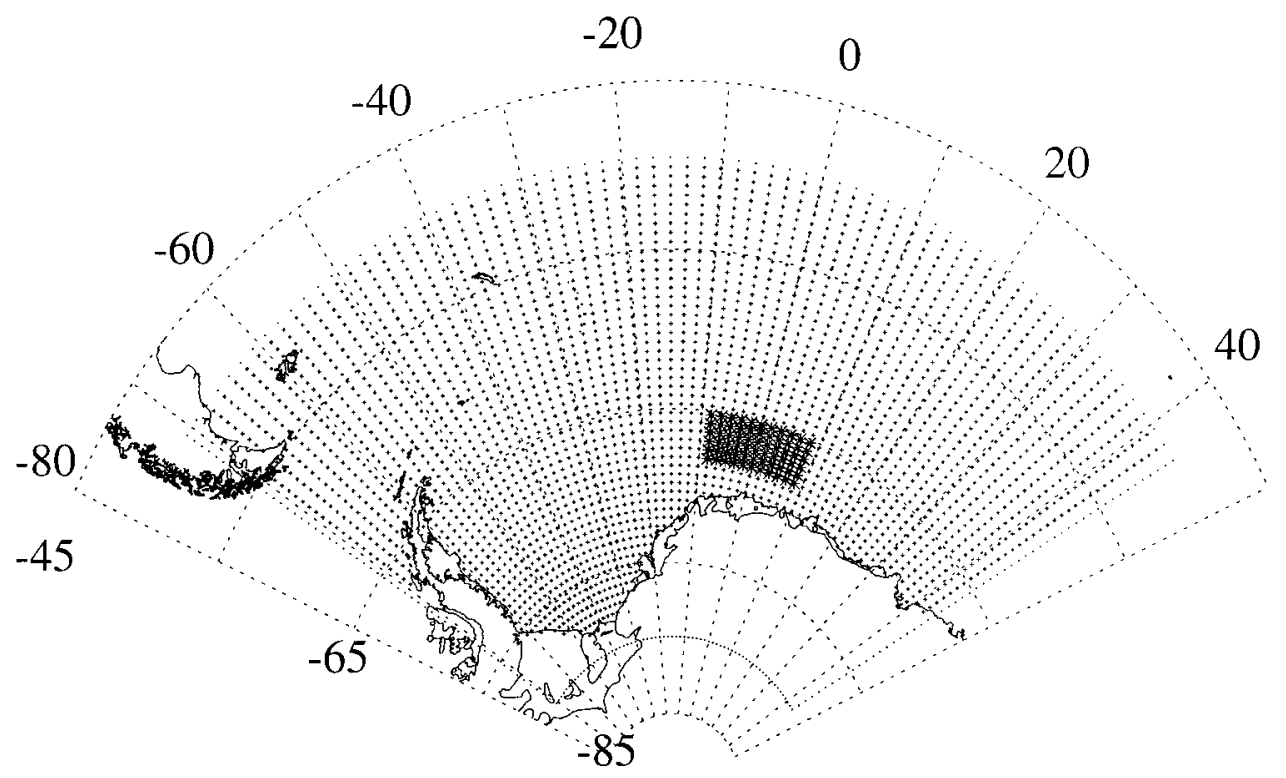

FIG. 2. Model domain. Bold marks indicate the area of preconditioned mixed layer.

counting for the effect of snow/ice conversion (Leppäranta 1983; Fischer 1995) is included.

To determine the oceanic heat flux prognostically, the model is coupled to the one-dimensional oceanic mixed layer-pycnocline model of Lemke (1987), as described by Lemke et al. (1990). For this study, a diagnostic calculation of the pycnocline upwelling velocity is added using the theory of Ekman pumping. If $A$ denotes the ice concentration, then the surface stress on top of the ocean is

$$
\boldsymbol{\tau}=(1-A) \boldsymbol{\tau}_{a}+A \boldsymbol{\tau}_{i w},
$$

where $\boldsymbol{\tau}_{a}$ and $\boldsymbol{\tau}_{i w}$ represent the atmospheric surface stress and the shear stress between ice and water, respectively. The upwelling velocity is calculated from curl $\boldsymbol{\tau}$ using the standard formula. Salt flux divergence in the upper ocean is parameterized by restoring to a constant value (33.8 psu, taken from the Southern Ocean Atlas) with a time constant of 1 yr. Ocean surface currents remain fixed. A more detailed description of the coupled model is given by Timmermann (1997).

The model domain represents the Atlantic sector of the Southern Ocean including the Weddell Sea (Fig. 2). The spatial resolution is $1.6875^{\circ}$ in zonal and $0.5625^{\circ}$ in meridional direction. A daily time step is applied. At continental boundaries a no-slip condition is prescribed, whereas ice may enter or leave the model domain due to advection at the oceanic boundaries of the model.

The atmospheric forcing is derived from daily values of air temperature, relative humidity, and wind fields obtained from seven years (1986-1992) of the global analyses of the European Centre for Medium Range Weather Forecasts (ECMWF). Spatially varying cloud- iness is interpolated from monthly climatological means of the International Satellite Cloud Climatology Program (ISCCP: Rossow et al. 1991). Precipitation is a prescribed constant in time and space according to Parkinson and Washington (1979). Prescribed ocean currents are constant in time and taken from estimates based on observed sea ice drift (Kottmeier and Sellmann 1996) and model simulations by H. Ross (1996, unpublished data). The ocean boundary conditions for temperature and salinity below the pycnocline are taken from the Hydrographic Atlas of the Southern Ocean.

In order to reach an equilibrium cycle the model is integrated for 7 years starting with an ice-free ocean and using the daily forcing data of 1986-92. The ice conditions on 31 December 1992 are used to restart the model. Within the following seven integration years the occurrence of a polynya is simulated.

\section{b. Lower-atmosphere model}

To allow for an atmospheric feedback, a simple description of a cyclonic wind system induced by a large upward heat flux above a polynya has been developed. The thermal wind is derived from analytical functions describing the atmospheric wind and temperature perturbation. Introduced by Smith (1979) to describe the influence of mountains on the atmosphere, the concept has been used to derive a quasigeostrophic flow solution for the circulation over Antarctica (Kottmeier and Stuckenberg 1986) as well as for a paleoclimate study of the circulation over the Scandinavian ice sheet during the last glacial maximum (Kottmeier and Meyer 1988). In the study presented here, the model is extended to a 


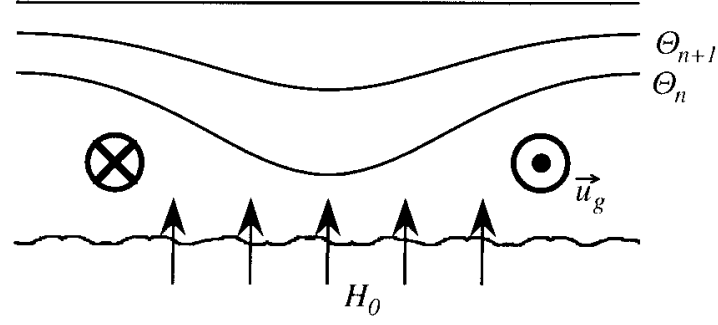

FIG. 3. Cyclonic circulation due to local warming of the lower atmosphere (Southern Hemisphere).

description of cyclonic motion that may vary in time. The modifications preserve the assumptions of hydrostatically balanced and quasigeostrophic flow and consequently the thermal wind relation between the temperature and flow fields.

The temperature profile in the atmosphere's basic state is specified by the potential temperature $\Theta_{O G}$ at the surface $(z=0)$ and the Brunt-Väisälä frequency $N$ by

$$
\Theta_{G}(z)=\Theta_{0 G}+\frac{N^{2} \bar{\Theta}}{g} z,
$$

where $\bar{\Theta}$ is a mean potential temperature and $g=9.8$ $\mathrm{m} \mathrm{s}^{-2}$. Equation (2) follows from the definition of $N^{2}$ and assumes a stable basic state, that is, $d \Theta / d z>0$. Perturbation of the basic thermal state is described by a vertical displacement function $\eta(x, y, z)$ of potential temperature surfaces. Assuming geostrophic and hydrostatically balanced flow and using the Boussinesq approximation, the thermal wind equations can be written as (Smith 1979)

$$
\begin{aligned}
f \frac{\partial u}{\partial z} & =N^{2} \frac{\partial \eta}{\partial y} \\
-f \frac{\partial v}{\partial z} & =N^{2} \frac{\partial \eta}{\partial x} .
\end{aligned}
$$

In these equations, $f$ represents the Coriolis parameter, and $u$ and $v$ are the geostrophic wind components in the $x$ and $y$ direction, respectively. In the region of a warm temperature perturbation, for example, over a polynya, isentropic surfaces are displaced downward. The displacement at a certain $(x, y)$ position decreases with height; at distances far from the sea surface, the displacement approaches zero. According to Eqs. (3) and (4) this is associated with a cyclonic motion decaying with height (Fig. 3).

Introducing a streamfunction $\Psi$, from which the velocities are derived using

$$
\begin{array}{r}
-u=\frac{\partial \Psi}{\partial y} \\
v=\frac{\partial \Psi}{\partial x},
\end{array}
$$

and integrating Eqs. (3) and (4) over $x$ and $y$, respectively, leads to

$$
\frac{\partial \Psi}{\partial z}=-\frac{N^{2}}{f} \eta(x, y, z) .
$$

According to Smith (1979) and Kottmeier and Stuckenberg (1986) $\Psi$ is chosen as the function of a point source:

$$
\Psi(x, y, z)=\frac{-S}{4 \pi r}
$$

where $S$ represents the source strength and

$$
r=\sqrt{\left(x-x_{0}\right)^{2}+\left(y-y_{0}\right)^{2}+f^{-2} N^{2}\left(z+z_{0}\right)^{2}}
$$

gives the distance from the location $\left(x_{0}, y_{0}, z_{0}\right)$ of the point source. For positive $z_{0}$ the point source is beneath the (sea) surface. The vertical coordinate $z$ is stretched by the factor $N / f$ to account for the vertical scale being much smaller than the horizontal scale of the flow. The vertical displacement function $\eta(x, y, z)$ results as

$$
\eta(x, y, z)=-\frac{S}{4 \pi f r^{3}}\left(z+z_{0}\right) .
$$

Assuming that the lowest $\Theta$ surface is bell shaped as given by

$$
\eta(x, y, 0)=h_{m} /\left(\frac{r_{h}^{2}}{r_{0}^{2}}+1\right)^{3 / 2},
$$

with $h_{m}$ as the maximum displacement and

$$
\begin{aligned}
& r_{h}^{2}=\left(x-x_{0}\right)^{2}+\left(y-y_{0}\right)^{2} \\
& r_{0}^{2}=\frac{N^{2}}{f^{2}} z_{0}^{2},
\end{aligned}
$$

the source strength is obtained as

$$
S=-4 \pi h_{m} \frac{N^{3}}{f^{2}} z_{0}^{2} .
$$

From (5), (6), (8), and (14) the velocity components can be derived as

$$
\begin{aligned}
& u=\frac{h_{m} N\left(y-y_{0}\right)}{\left[\frac{r_{h}^{2}}{r_{0}^{2}}+\left(\frac{z}{z_{0}}+1\right)^{2}\right]^{3 / 2} r_{0}}, \\
& v=\frac{-h_{m} N\left(x-x_{0}\right)}{\left[\frac{r_{h}^{2}}{r_{0}^{2}}+\left(\frac{z}{z_{0}}+1\right)^{2}\right]^{3 / 2} r_{0}} .
\end{aligned}
$$

The values of $N$ and $f$ and the coordinates $\left(x_{0}, y_{0}\right)$ of the point source need to be adequately chosen. The equations additionally contain the maximum vertical displacement $h_{m}$ of the $\Theta$ surfaces and the vertical coordinate $z_{0}$ of the point source of the streamfunction as unknown parameters, where the value of $z_{0}$ determines 
the width of the bell-shaped $\Theta$ surfaces. The analytical model thus contains only very few free parameters.

In extension of the earlier applications, $h_{m}$ is calculated diagnostically from the turbulent heat flux in the polynya region. Assuming conservation of heat, warming of an atmospheric volume of thickness $d z$ by a vertical heat flux $H$ is described by

$$
\int_{0}^{t^{*}} \frac{d H}{d z} d t=-\rho c_{p} \Delta T
$$

where $\Delta T$ is the change of temperature within the time interval $t^{*}$. The air density is denoted by $\rho$, and $c_{p}$ is the specific heat at constant pressure. The warming of the lower atmosphere is related to the surface heat flux by spatially integrating this equation:

$$
H_{0} F t^{*}=c_{p} \int_{x_{1}}^{x_{2}} \int_{y_{1}}^{y_{2}} \int_{0}^{z_{m}} \rho(x, y, z) \Delta T(x, y, z) d z d y d x,
$$

where $H_{0}$ is the average surface heat flux in the time interval $t^{*}$. Here $F$ represents the area of turbulent heat exchange-the polynya-so $H_{0} F t^{*}$ is the heat transfered to the atmosphere. Using Eqs. (2), (10), and (14), the equation of state of an idealized gas, and the definition of potential temperature as well as the exponential decay of pressure with height, an equation for $h_{m}$ as a function of $H_{0}$ and $t^{*}$ can be derived (Timmermann 1997) from Eq. (17) as

$$
h_{m}=-\frac{2 \pi R H_{0} F t^{*}}{c_{p} p_{G 0}\left(\bar{\Theta} N^{2}\right) / g}\left(\int_{0}^{z_{m}} \int_{0}^{r_{h}^{\max }} \frac{\left(\frac{z_{G}}{z_{0}}+1\right) e^{-z / z_{s}}}{\left(\Theta_{0 G}+\frac{\bar{\Theta} N^{2}}{g} z\right)\left[\frac{r_{h}^{2}}{r_{0}^{2}}+\left(\frac{z_{G}}{z_{0}}+1\right)^{2}\right]^{3 / 2}} r_{h} d r_{h} d z\right)^{-1},
$$

where $R$ is the specific gas constant for dry air $(R=287$ $\left.\mathrm{J} \mathrm{kg}^{-1} \mathrm{~K}^{-1}\right), p_{G 0}$ is the sea level pressure in the basic thermal state, and $z_{s}$ is the scale height of pressure decay. A $\Theta$ surface intersecting the point $(x, y, z)$ in the disturbed state is displaced from the level $z_{G}$ according to

$$
\begin{aligned}
z_{G}(x, y, z) & =z-\eta\left(x, y, z_{G}\right) \\
& =z-\frac{h_{m}\left(\frac{z_{G}}{z_{0}}+1\right)}{\left[\frac{r_{h}^{2}}{r_{0}^{2}}+\left(\frac{z_{G}}{z_{0}}+1\right)^{2}\right]^{3 / 2}} .
\end{aligned}
$$

From this (implicit) relation $z_{G}$ is calculated using the Newton scheme of iteration at each point $(x, y, z)$ of the integral (18), which is also calculated numerically. The equations are combined using a simple scheme of iteration, starting with an estimated value of $h_{m}$ and recalculating Eq. (18) until $\left|h_{m}^{\text {(new) }}-h_{m}^{\text {(old) }}\right|<10 \mathrm{~m}$. The horizontal integration limit is chosen as $r_{h}^{\max }=1000$ $\mathrm{km}$, which is larger by a factor of 1.5 than the maximum radius of the polynya. According to simulations of Law et al. (1992) using a general circulation model, moist convection south of $50^{\circ} \mathrm{S}$ is restricted to a maximum height of $3000 \mathrm{~m}$. This value is applied as the limit $z_{m}$ for vertical integration. With these assumptions the distribution of heat emerging from the polynya into the atmosphere is prescribed.

As the thermal wind system is induced by a temperature perturbation in the lower troposphere, the model is forced by the heat flux anomaly at the ocean-atmosphere interface. Instead of taking the absolute value of the ocean-atmosphere heat flux, only the latent and sensible heat flux difference between the polynya and the standard run has to be taken into account. The differences in the long- and shortwave radiation flux divergences between standard and polynya run are negligible compared to the turbulent heat fluxes.

Now, only the value of $t^{*}$ remains to be fixed. It corresponds to the characteristic residence time of an air mass over the polynya and to the effect of advection by the mean "background" flow. For a prescribed heat flux at the ocean surface, $t^{*}$ determines the absorbed heat and thus the magnitude of the temperature perturbation in the lower atmosphere. The influence of different values for $t^{*}$ is investigated in the polynya simulations.

Adjusting the width of the bell-shaped $\Theta$ surfaces and thus of the thermal wind system to the maximum size of the polynya, the value of $z_{0}$ was fixed to $6000 \mathrm{~m}$ (corresponding to $r_{0} \approx 600 \mathrm{~km}$ ). The Brunt-Väisälä frequency $N$ is chosen as $0.01 \mathrm{~s}^{-1}$.

Equation (15) gives the thermal wind at each point $(x, y, z)$ of the model, related to a fictitious motionless height $z=\infty$. Choosing the upper limit of the vertical integration in (18) as $3000 \mathrm{~m}$, it is assumed that the thermal perturbation is confined to the lower $3000 \mathrm{~m}$ of the atmosphere. The effect of the thermal wind has to be restricted to this layer. The geostrophic wind at $10-\mathrm{m}$ height consequently is calculated as the difference be- 

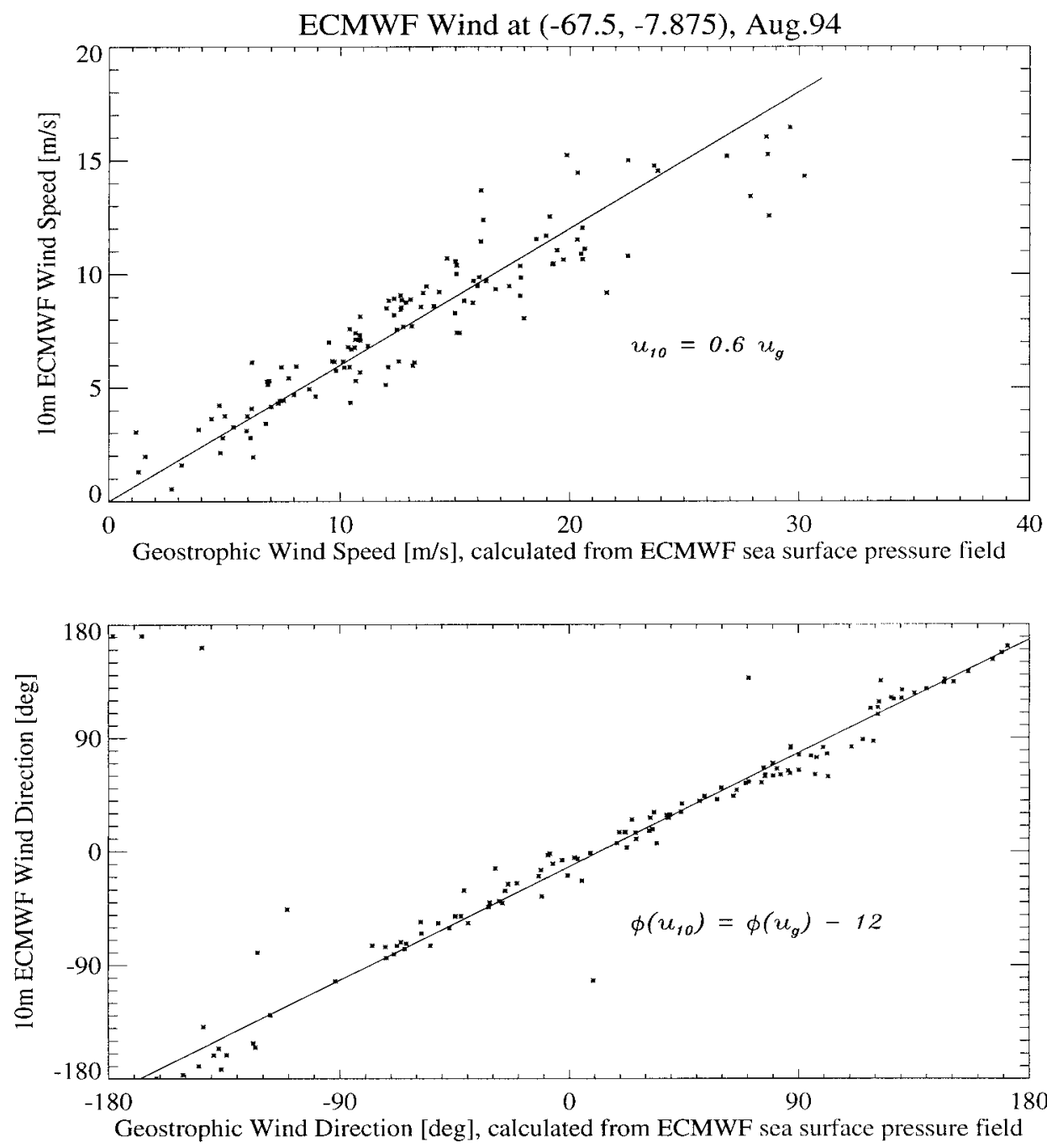

FIG. 4. Comparison of speed (top) and angle (bottom) of the ECMWF 10-m wind and the geostrophic wind calculated from the ECMWF sea surface pressure field at the same position for the analyses of August 1994. As an effect of friction in the planetary boundary layer, wind speed slows down by a factor 0.6 and wind direction turns $12^{\circ}$ to the right.

tween the thermal wind components at $z=10 \mathrm{~m}$ and $z=3000 \mathrm{~m}$

This simple atmospheric model provides the thermal wind as a function of the vertical heat flux in the polynya region, but it does not account for effects of the largescale atmospheric flow. The investigated polynya, however, is located in the region of the circumpolar trough where migrating low pressure cells are linked with a characteristic flow pattern. To derive a forcing dataset with realistic daily variability, the calculated thermal wind is combined with daily means of the ECMWF wind field by superposition of the geostrophic winds. As only the ECMWF 10-m winds were available for this study, we deduced the geostrophic winds from those. The description of the planetary boundary layer included in the ECMWF assimilation scheme could not be used for this purpose as some of the variables used there are not available in our simple approach. Instead, the basic relationship between ECMWF 10-m and geostrophic winds was obtained by calculating geostrophic winds from the ECMWF sea surface pressure field and comparing these with the ECMWF 10-m wind at the same position (Fig. 4). Geostrophic and 10-m wind speed ( $\left|\mathbf{u}_{g}\right|$ and $\left.\left|\mathbf{u}_{10}\right|\right)$ and the deviation angle between the 10-m wind $\mathbf{u}_{10}$ and the geostrophic wind $\mathbf{u}_{g}$ can be reasonably related by

$$
\left|\mathbf{u}_{g}\right|=\frac{\left|\mathbf{u}_{10}\right|}{0.6}, \quad \phi_{\mathbf{u}_{g}}=\phi_{\mathbf{u}_{10}}+12^{\circ} .
$$

The geostrophic winds derived with these equations are superimposed by the thermal wind components (15). From the resulting geostrophic wind field, modified $10-\mathrm{m}$ winds are obtained again using (21). 
Generally, the atmospheric variability is large on timescales shorter than those relevant for sea ice. With respect to computing time, this is the major problem in investigating the interaction of atmosphere and sea ice. The simple model applied here is not able and not meant to replace an atmospheric circulation model but gives an estimate on the velocity of a thermal wind system induced by a surface heat flux anomaly. It contains a purely diagnostic description of the atmospheric response and is computationally inexpensive, which easily allows an integration of the coupled model over several years.

\section{Standard experiment}

In contrast to Lemke et al. (1990) who used spatially and temporally constant boundary conditions for temperature and salinity below the pycnocline, in this study the observed spatial patterns of temperature and salinity in the deep ocean are taken from the Hydrographic Atlas of the Southern Ocean (Olbers et al. 1992). As an example for the standard experiment, the sea ice thickness and the entrainment heat flux in a typical winter month are displayed in Fig. 5. The results indicate that the present model setup yields a realistic description of the conditions in the Weddell Sea.

\section{Polynya experiments}

Similar to the study of Lemke et al. (1990), the polynya experiments are initiated by modeling the entrainment of warm salty water induced by warm subsurface eddies at a time when the mixed layer tends to deepen. For 50 days in the first year of integration, the pycnocline upwelling velocity is set to a value of $1.3 \mathrm{~m} \mathrm{~d}^{-1}$ (which is about ten times larger than the mean upwelling velocity in the standard experiment) and the mixed layer model bottom temperature $T_{b}$ is increased by $1^{\circ} \mathrm{C}$. The preconditioned area extends over $300000 \mathrm{~km}^{2}$ (bold marks in Fig. 2). This perturbation is applied starting from Julian day 52. In the annual cycle, this is the period when the mixed layer depth increases due to cooling and (later) brine rejection from new ice growth. At Julian day 52, the mixed layer depth has just exceeded 20 $\mathrm{m}$ and the ocean is not yet ice covered, which is essential to achieve the formation of a polynya. In case a solid ice cover has already formed at the time of the perturbation, vertical heat flux would melt part of the sea ice cover; the associated freshwater flux would stabilize the stratification of the upper ocean, thus suppressing further entrainment heat flux.

Using the sea ice-mixed layer model without any atmospheric feedback, the effect on the simulated sea ice distribution is quite similar to the polynya experiment of Lemke et al. (1990). Due to the increased upwelling, warm and salty water is entrained into the mixed layer. While salt remains in the ocean, heat is lost to the atmosphere. As a result of the reduced mixed layer depth, mixed layer density increases rapidly. Thus, deep convection is induced finally leading to a mixed layer depth of almost $500 \mathrm{~m}$. The increased entrainment heat flux (up to $500 \mathrm{~W} \mathrm{~m}^{-2}$ for a short time interval) prevents the formation of sea ice for the entire freezing period. The extent of the emerging polynya (Fig. 6) shrinks in the course of winter due to the advection of sea ice, but it remains open until the sea ice cover of the whole area retreats. In the second year of integration, a smaller polynya occurs, but at Julian day 205 the area of open water is closed due to the advection of sea ice. After five years of integration the system has again reached the annual cycle of the reference experiment.

At this point, the question arises whether the atmospheric feedback is able to prohibit the import of sea ice into the polynya. As we will see, the answer depends on the assumptions concerning the residence time $t^{*}$. Four experiments were performed with $t^{*}=7 \mathrm{~d}, 10 \mathrm{~d}$, $12 \mathrm{~d}$, and $14 \mathrm{~d}$, which represents a mean atmospheric cross-polynya flow between 1.2 and $0.6 \mathrm{~m} \mathrm{~s}^{-1}$, respectively.

In the simulations with $t^{*}=7 \mathrm{~d}$ and $t^{*}=10 \mathrm{~d}$, the lifetime of the polynya does not differ significantly from the polynya experiment without any atmospheric feedback. In contrast to the ice-model-only integration, however, the spatial extent of the polynya remains constant or (in case of $t^{*}=10 \mathrm{~d}$ ) even grows during the course of winter, as the observed Weddell polynya did. The cyclonic thermal wind system with typical maximum velocities of $10 \mathrm{~m} \mathrm{~s}^{-1}$ apparently is not able to prevent the import of sea ice. As the net growth rate within the polynya area indicates, thermodynamic sea ice formation in the polynya area starts some time after the grid cells have been covered by imported sea ice. This proves that advection is the main feature reducing the lifetime of the polynya.

Figure 7 displays time series of the polynya area (defined as the area of grid cells with an ice concentration below $15 \%$ ), the ice thickness in the polynya center and the maximum thermal wind speed taken from the experiment with $t^{*}=12 \mathrm{~d}$. As an effect of the atmospheric feedback, the polynya occurs in three subsequent years. The typical maximum speed of the cyclonic thermal wind system is $15 \mathrm{~m} \mathrm{~s}^{-1}$ in the first two years and $6 \mathrm{~m}$ $\mathrm{s}^{-1}$ in the third year. Apparently, in the latter case the cyclonic flow is too weak to prevent the import of sea ice.

Setting $t^{*}=14 \mathrm{~d}$, the typical maximum speed of the cyclonic wind system rises to $18 \mathrm{~m} \mathrm{~s}^{-1}$ and thus is of the same order of magnitude as the cyclones contained in the large-scale ECMWF wind field. The turbulent fluxes of latent and sensible heat that are responsible for its existence exceed those of the reference experiment by a factor of 10 and are consistent with measurements over Arctic leads (Andreas et al. 1979). Latent and sensible heat fluxes are of the same order of magnitude (Fig. 10)

In each winter period of this seven-year integration, 

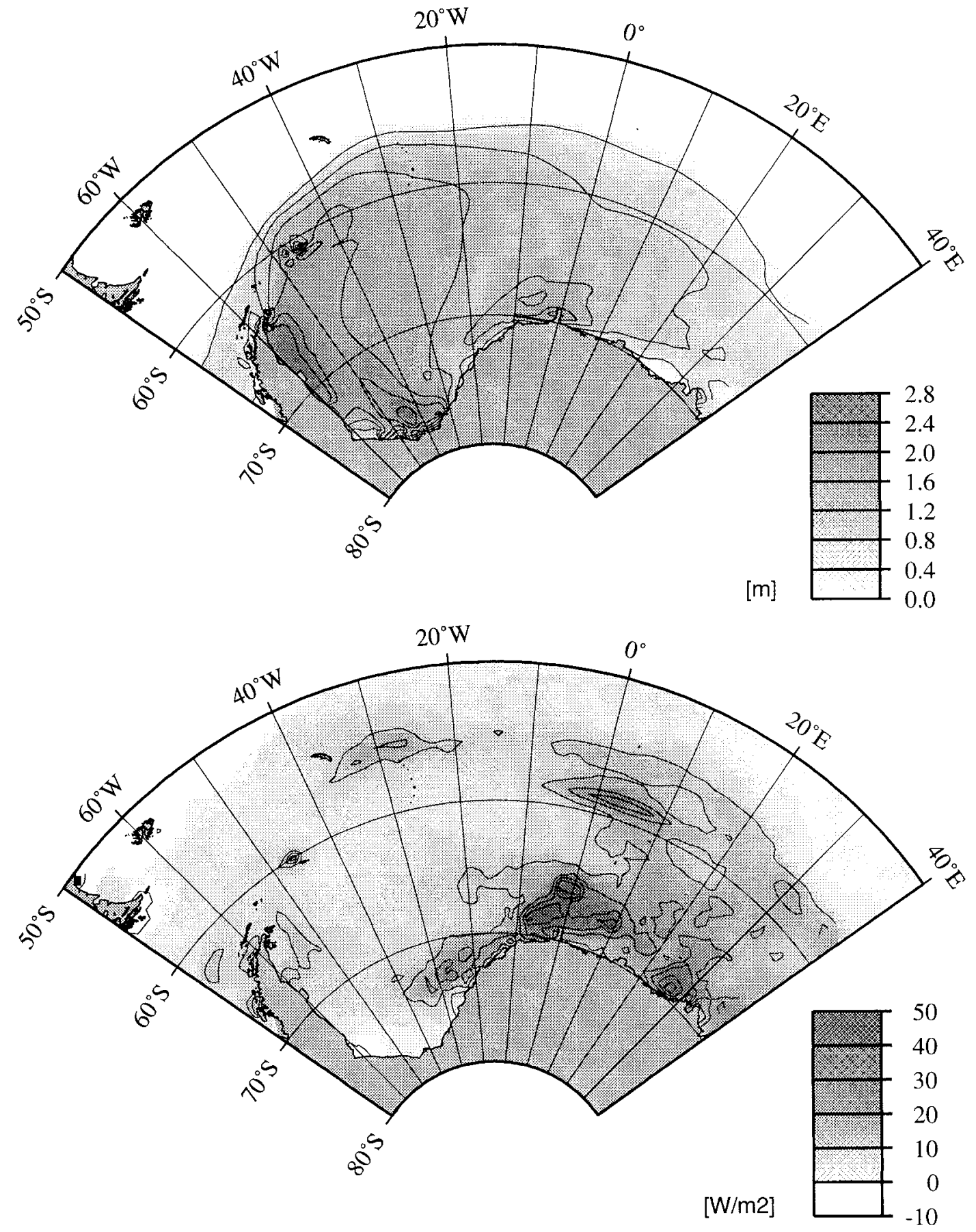

FIG. 5. Ice thickness (top) and entrainment heat flux at the mixed layer base (bottom) in August of the second year of the reference integration. Contour intervals are $0.4 \mathrm{~m}$ and $10 \mathrm{~W} \mathrm{~m}^{-2}$, respectively.

a polynya with an areal extent of $200000-300000 \mathrm{~km}^{2}$ occurs. In the fifth winter, ice cover grows up to a thickness of $40 \mathrm{~cm}$; in all the other years the ocean remains virtually ice free.

Besides the mean ice concentration in September (which is the time of maximum ice extent) of the seventh year of integration, Fig. 8 (top) displays the mean 10-m wind speed. In addition to the typical large-scale pattern, a distinct cyclonic eddy is visible. This leads to a divergent ice drift (Fig. 8, bottom) and-via Ekman pumping and increased entrainment-to an enhanced vertical oceanic heat flux (Fig. 9). Together, these features prevent both the freezing and the import of sea ice. 


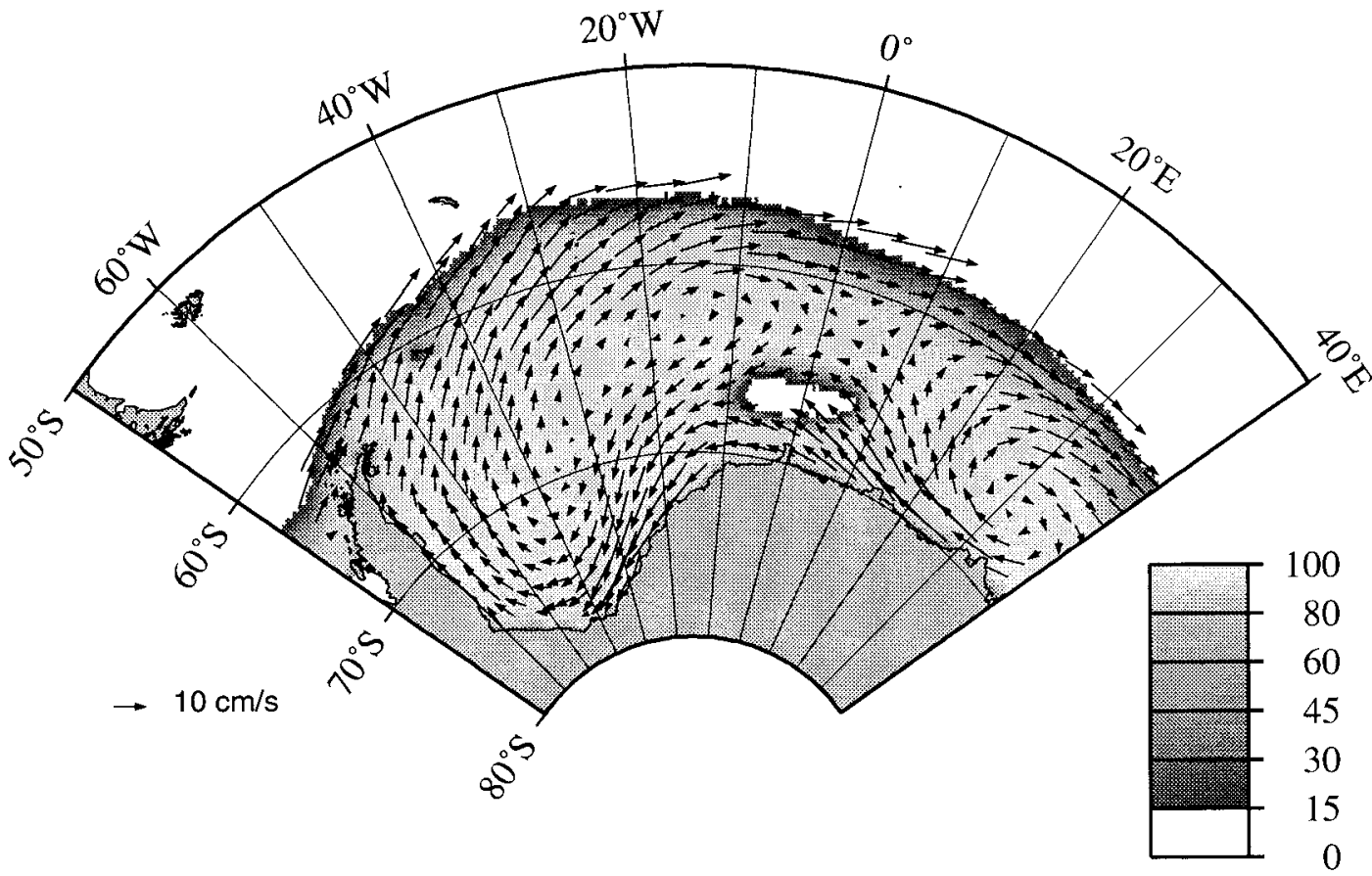

FIG. 6. Ice concentration and mean drift in July of the first year of integration in a polynya experiment without atmospheric feedback.

a)

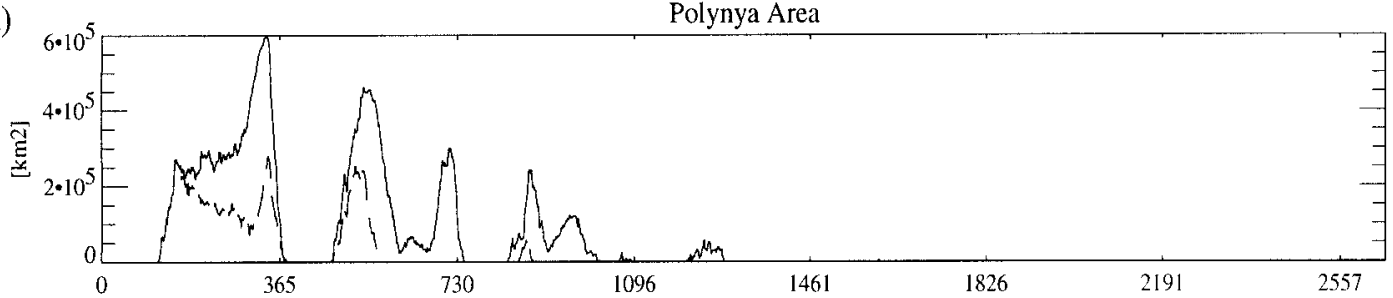

b)

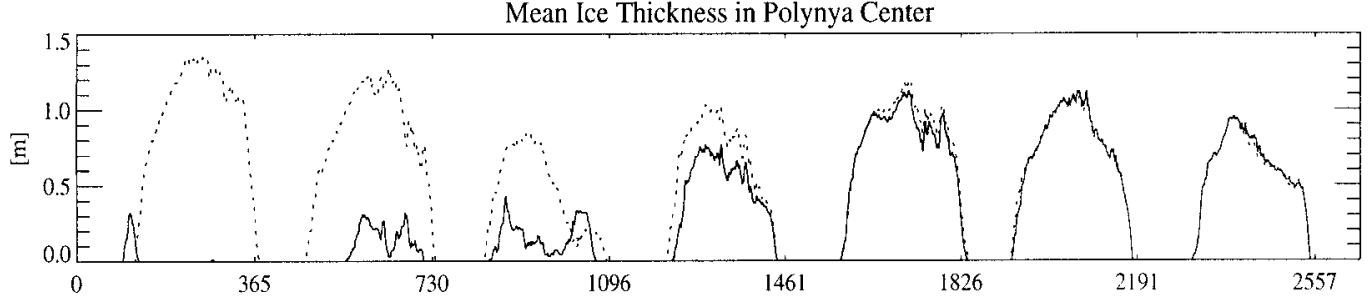

c)

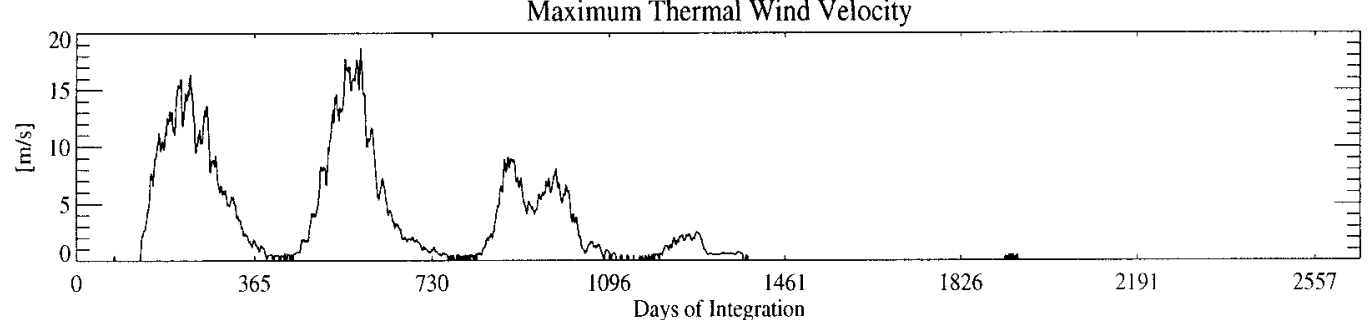

FIG. 7. Time series of (a) the polynya area, (b) the ice thickness in the polynya center, and (c) the maximum thermal surface wind taken from the polynya experiment with atmospheric feedback and $t^{*}=12 \mathrm{~d}$ (solid lines). The dashed line in (a) indicates the polynya extent in the polynya experiment without any atmospheric feedback. The dotted line in (b) indicates the ice thickness at the respective position in the reference experiment. 

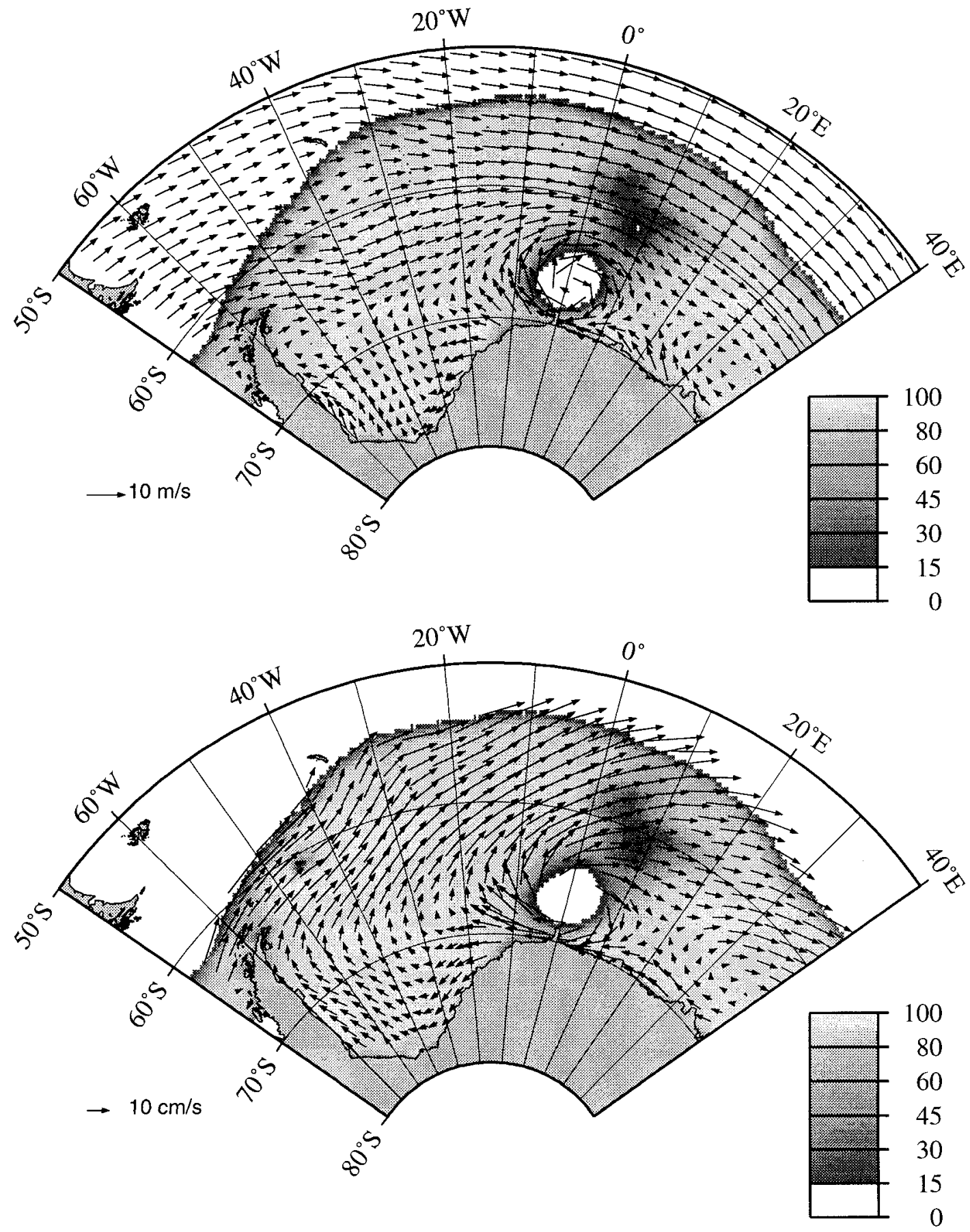

FIG. 8. Mean ice concentration and 10-m wind speed (top), mean ice concentration, and sea ice drift (bottom) in September of the seventh year of integration taken from a polynya experiment including atmospheric feedback assuming a mean atmospheric cross polynya flow of $0.6 \mathrm{~m} \mathrm{~s}^{-1}$. $\left(t^{*}=14 \mathrm{~d}\right.$.)

Figures 9 and 10 present the evolution of the perturbed system. During the winter period, the thermal wind system is strong enough to keep the preconditioned ocean area uncovered. As an implication of the entrainment of warm, salty deep water, not only the heat but also the salt content of the oceanic mixed layer is in- creased. As a result, the mixed layer salinity exceeds the values of the reference experiment and those of the nonpreconditioned vicinity by about $0.1 \mathrm{psu}-\mathrm{even}$ in the summer period. At the beginning of the following winter, the mixed layer density in the polynya area is still increased so that atmospheric cooling alone is able 
a)

Polynya Area

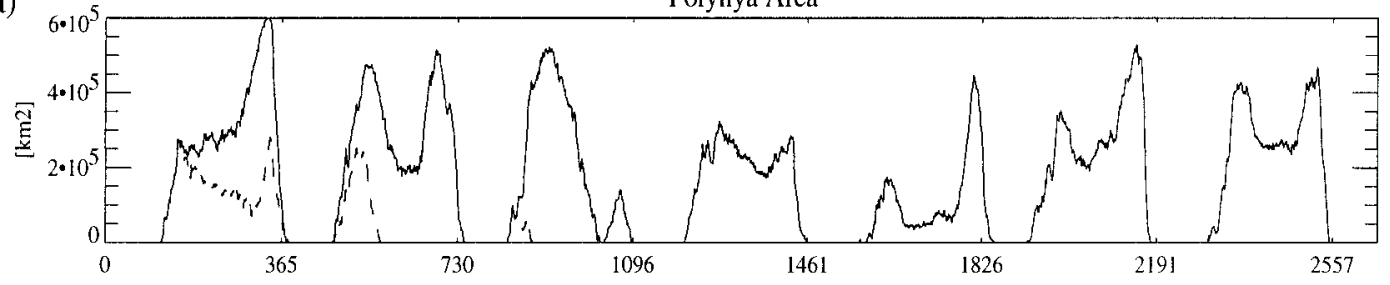

b)

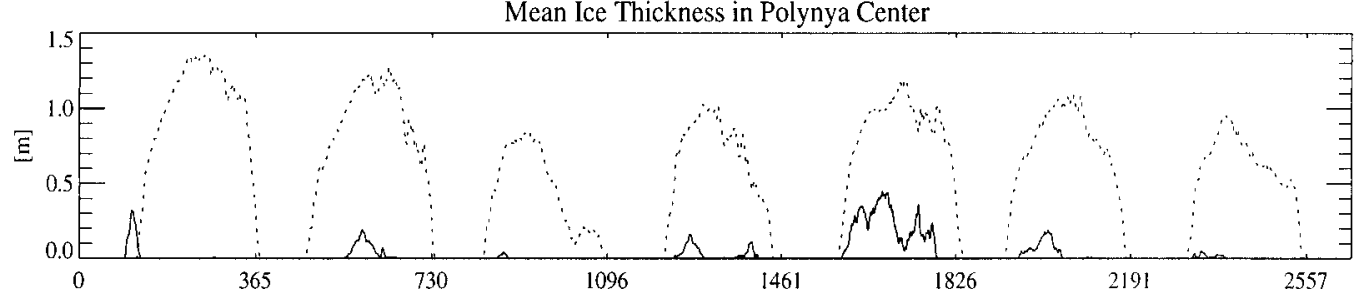

c)

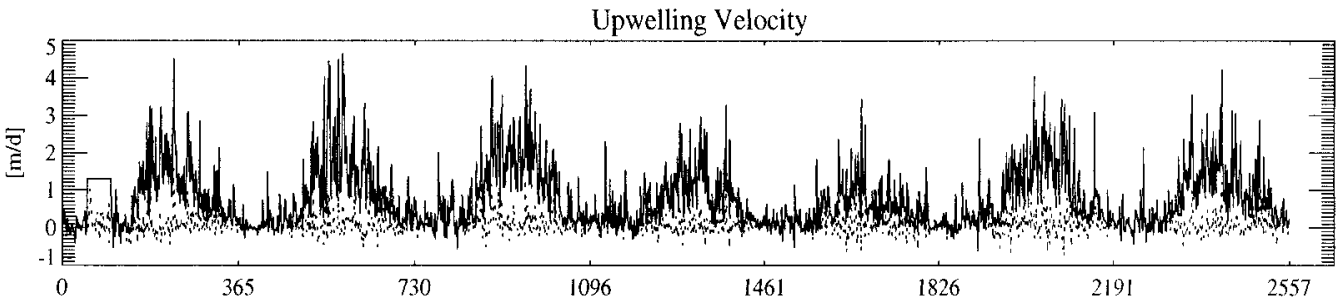

d)

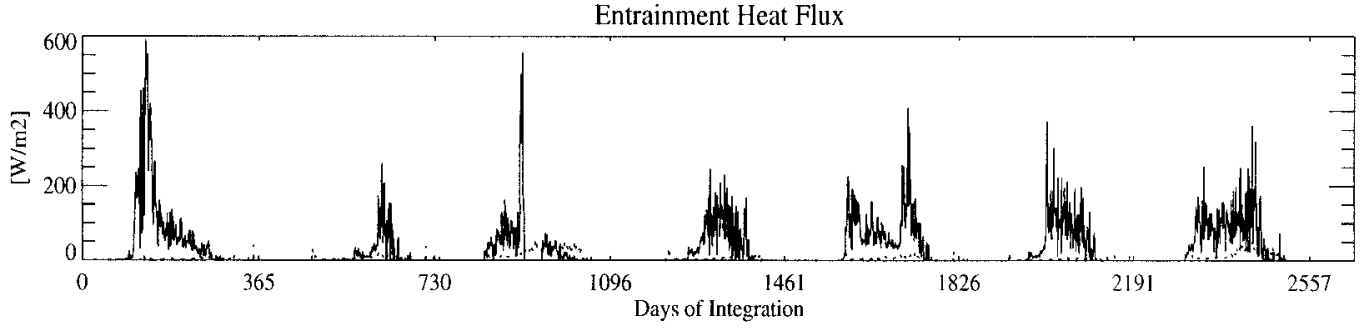

FIG. 9. Time series of (a) polynya extent, (b) ice thickness in the polynya center, (c) pycnocline upwelling velocity, and (d) entrainment heat flux into the oceanic mixed layer taken from the polynya experiment with atmospheric feedback and $t^{*}=14 \mathrm{~d}$ (solid lines). The dashed line in (a) indicates the polynya extent in the polynya experiment without any atmospheric feedback. The dotted lines in (b) to (d) indicate the respective values of the reference experiment.

to induce intensified entrainment, which delays the formation of sea ice. By this time, the undisturbed surrounding of the preconditioned area is already ice covered so that a thermal wind system forms again.

To keep this process running, the mean atmospheric cross-polynya flow has to be weaker than about $1 \mathrm{~m} \mathrm{~s}^{-1}$ during the entire winter season. One would expect that this situation should be correlated with small surface wind velocities. Under such conditions, local anomalies (like the thermal wind system induced by the increased turbulent heat flux in the polynya area) would be more significant compared with the large-scale "background" wind system. On the other hand, turbulent heat fluxes at the ocean surface are assumed to be proportional to the 10-m wind speed. Reduced wind speed consequently leads to reduced turbulent heat flux and thus to a reduced thermal perturbation of the lower atmosphere. These effects will be discussed in the next section.

\section{Sensitivity experiments \\ a. Reduced ECMWF wind speed}

To check whether weak surface winds would promote or complicate the conservation of a polynya, two polynya experiments with a modified ECMWF wind field were performed and compared with the "normal" polynya experiment. To construct a fictitious surface wind with realistic distribution but reduced speed, the ECMWF wind was multiplied with a factor of 0.75 and 0.5 , respectively.

Whereas in the first case (factor 0.75 ) no significant 
a)

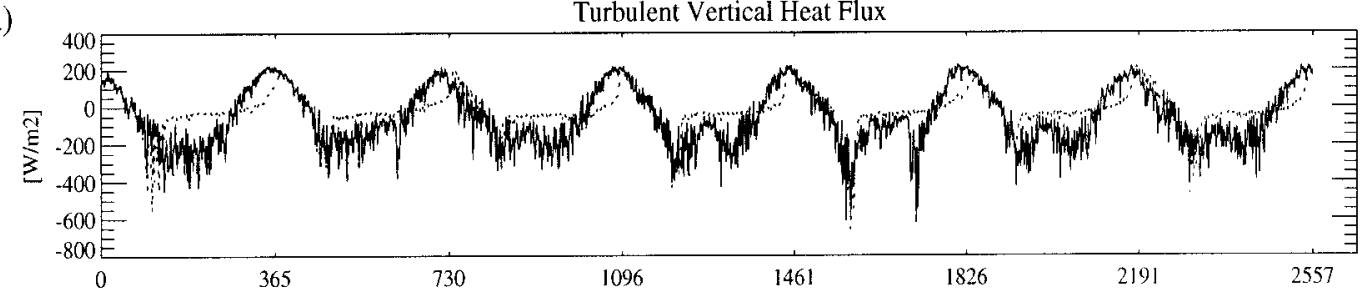

b)

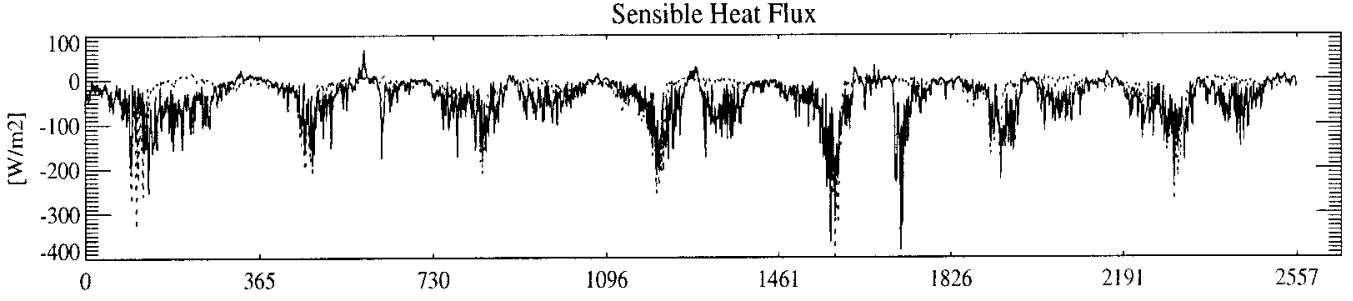

c)

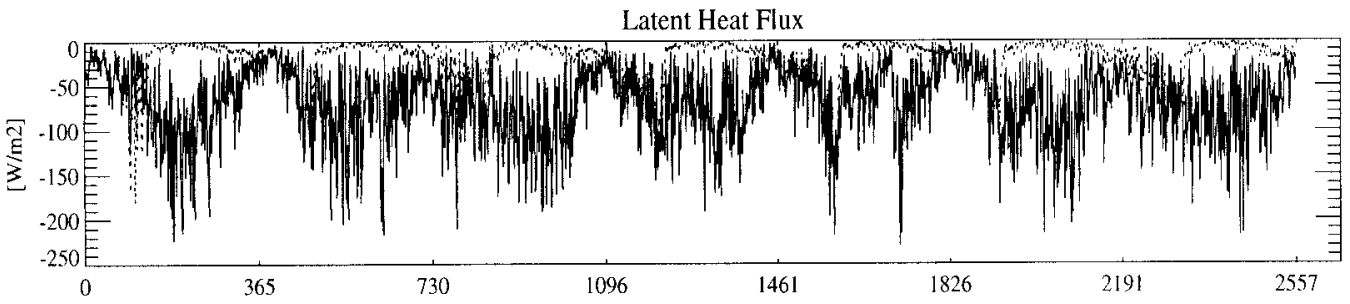

d)

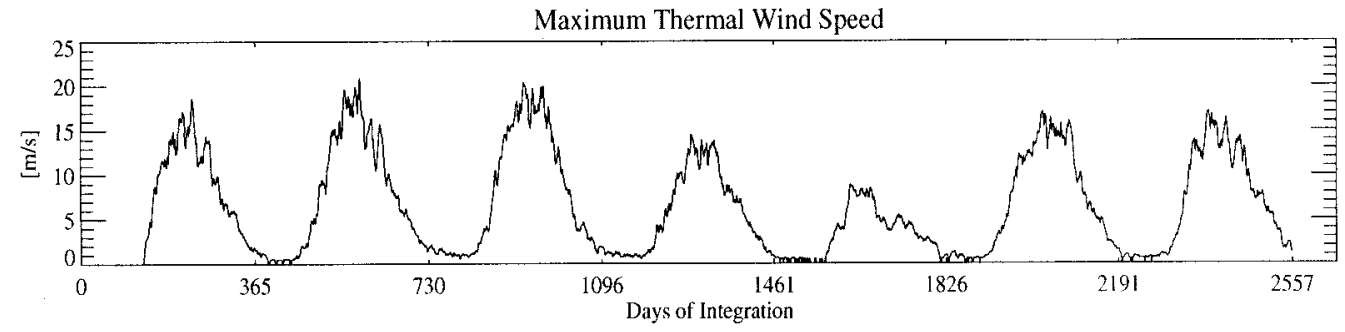

FIG. 10. Time series of (a) vertical turbulent heat flux (negative values denote a flux from the ocean to the atmosphere), (b) sensible, and (c) latent heat flux, and (d) the maximum thermal wind speed taken from the polynya experiment with atmospheric feedback and $t^{*}=14 \mathrm{~d}$ (solid lines). The dotted lines in (a) to (c) indicate the respective values of the reference experiment.

alteration is to be recorded, the polynya extent and lifetime are reduced significantly in the second case (factor 0.5). As an effect of the reduced ECMWF wind speed, the strength of the thermal wind system and its impact on the polynya are reduced. In addition to that, the increase of the oceanic mixed layer density at the beginning of winter is smaller. Consequently, in this experiment, the mixed layer depth in the preconditioned area does not exceed $190 \mathrm{~m}$, and the entrainment heat flux exceeds $100 \mathrm{~W} \mathrm{~m}^{-2}$ only for short time intervals. Hence, lifetime and extent of the polynya are reduced, even compared with the polynya experiment without any atmospheric feedback.

\section{b. Increase of polynya area}

As the absorbed amount of heat in the atmosphere is, according to Eq. (17), proportional to $t^{*}$ as well as to the area $F$ of enhanced turbulent heat exchange, one would expect that an expansion of the preconditioned area would lead to a longer lifetime of the polynya. When the extent of the preconditioned area is doubled, however, the extent of the polynya does increase as well as the strength of the thermal wind system, but the polynya's lifetime changes only by a few days. This leads to the conclusion that the extended lifetime of the polynya in the experiments with $t^{*}=12 \mathrm{~d}$ and $t^{*}=14$ $\mathrm{d}$ is not only a result of the intensified cyclonic wind but also of the increased response time of the lower atmosphere, which is caused by the longer time interval over which the surface heat flux is averaged.

This is confirmed by a further sensitivity experiment. An arbitrary increase of the cyclonic wind by $50 \%$ leads to an increased polynya area but not to a longer polynya lifetime. 


\section{c. Modified initialization}

As the ECMWF wind is the only consistent forcing field with interannual variations, it seems to be possible that the results of the experiment depend on the year of the polynya initialization. Several experiments with different years of initialization as well as model integrations with the wind field of the same year repeated seven times, however, reveal no significant difference.

\section{d. Parameterization of turbulent heat fluxes}

To investigate the sensitivity concerning different parameterizations of the turbulent heat exchange between ocean and atmosphere, several experiments with different values for $t^{*}$ were performed setting the exchange coefficients, which in the experiments so far were $C_{s}=$ $C_{l}=1.75 \times 10^{-3}$ according to Parkinson and Washington (1979), to $C_{s}=C_{l}=1.3 \times 10^{-3}$. As described above, the reduced heat exchange between ocean and atmosphere leads to a smaller thermal perturbation and thus to a weaker thermal wind. Consequently, the result is a reduced impact on the sea ice cover. In this case $t^{*}$ has to be $14 \mathrm{~d}$ or longer to achieve a significant prolongation of the polynya lifetime.

\section{e. Width of the cyclonic wind system}

As already explained, $z_{0}$ is a measure of the width of the bell-shaped isotherms in the thermally perturbed lower atmosphere. Higher values of $z_{0}$ lead to larger extent and decreased strength of the cyclonic wind system. The experiments described above were performed with $z_{0}=6000 \mathrm{~m}\left(R_{0} \approx 600 \mathrm{~km}\right)$. Varying $z_{0}$ between 5000 and $8000 \mathrm{~m}$ reveals no significant changes. For $z_{0}$ $>8000 \mathrm{~m}\left(R_{0}>800 \mathrm{~km}\right)$, however, the weakening of the cyclonic wind system reduces its impact on the sea ice cover.

\section{Conclusions}

Considering the interaction between sea ice and atmosphere in a simplified way, experiments with a dynamic-thermodynamic sea ice-mixed layer model indicate that the development of a self-conserving low pressure system is able to promote the repeated occurence of a large polynya in the Southern Ocean.

Initialized by a preconditioning of the oceanic mixed layer, the perturbation develops in time by warming the lower atmosphere above the polynya during the ice covered season and by partly conserving an increased mixed layer salinity during the summer period.

To allow for this process, the mean "background" atmospheric cross-polynya flow apparently has to be less than about $1 \mathrm{~m} \mathrm{~s}^{-1}\left(t^{*}>10 \mathrm{~d}\right)$. This situation, which can be regarded as a persistent preconditoned atmosphere, is not related to slow surface winds. The sensitivity experiments indicate that weak surface winds do not favor the occurence and maintenance of a polynya.

Whereas at first glance this seems to be a contradiction in itself, ECMWF analyses reveal that the vector mean of surface wind velocities south of $65^{\circ} \mathrm{S}$ in the winter season is only a few meters per second (Kottmeier et al. 1996). The 10-m monthly mean wind speed ranges from 0 to about $7 \mathrm{~m} \mathrm{~s}^{-1}$, and the mean vector generally has an eastward component north of $65^{\circ} \mathrm{S}$ and a westward component south of $70^{\circ} \mathrm{S}$ in the region of interest. This reflects that the depressions passing along have opposite wind directions in the different sectors, which partly average out in monthly means. The transition zone between the strong, persistent mean westerly flow at about $62^{\circ} \mathrm{S}$ and the coastal easterlies south of $68^{\circ} \mathrm{S}$ may be a place where the advection may become rather weak from time to time-and this actually is the place where the Weddell Polynya occurred.

Assuming a situation like this, increased vertical heat fluxes in the open-water area induce a local warming of the lower atmosphere. The corresponding cyclonic thermal wind system modifies the sea ice drift into a divergent motion and increases the vertical oceanic heat flux due to Ekman pumping. In case a cyclonic thermal wind of about $15 \mathrm{~m} \mathrm{~s}^{-1}$ (or higher) is induced, a largescale polynya is maintained over the entire winter period.

As an effect of Ekman pumping, not only heat but also salt is injected into the oceanic mixed layer. As timescales of transport in the ocean are long, the increased mixed layer salinity is nearly persistent over the summer period. Hence, at the beginning of the following winter the mixed layer density still is high so that even atmospheric cooling leads to intense entrainment. This effect maintains the perturbation over several yearsdespite the short timescales that are relevant for the atmosphere.

A further requirement for the formation of a secondary low pressure system is a sufficiently large polynya area. Evidently, the quantitiy of heat injected into the atmosphere above an area of open water grows with its extension. In the case when the polynya area is too small, thermal perturbation of the lower atmosphere in the respective region will be weak so that no significant influence on the sea ice distribution is to be expected. In the polynya experiments, the "critical extension" is of the order of $100000 \mathrm{~km}^{2}$; as the interaction strongly depends on the dynamic state of the atmosphere, it is impossible to give an exact value.

In contrast to the observations of 1974-76, the simulated polynya does not move eastward in the course of time. This can easily be explained, as the one-dimensional mixed layer model does not contain any horizontal advection. The movement of the preconditioned area with the mean oceanic flow therefore cannot be considered. As the area of increased turbulent heat flux cannot move either, the location of the atmosphere's thermal perturbation in the model is fixed. 
If the numerical description of both the mixed layer and the atmosphere were modified in a suitable way, we expect that the motion of the observed Weddell polynya could be described as well: In reality, sea ice and ocean move with different speeds in different directions, but, as the observations indicate, the location of the sea ice anomaly is given by the position of the preconditioned region of the ocean. As the location of the atmospheric thermal perturbation is connected with the open water area, local interaction between atmosphere, ocean, and sea ice would not change. Concerning the processes relevant for formation and maintenance of a polynya, major changes are not expected as long as the timescale of diffusion does not change.

The polynya lifetime after being initialized by a warm eddy depends on the large-scale atmospheric circulation: Only in case the mean cross-polynya flow is unusually small (below $1 \mathrm{~m} \mathrm{~s}^{-1}$ and thus distinctly smaller than in the quasi climatology of the ECMWF analyses), heat injection through an area of open water is able to create a sufficiently large thermal perturbation in the lower atmosphere.

The question arises whether a large polynya itself can create these conditions by modifying the general atmospheric circulation. An answer could be found replacing the simple diagnostic model used here by an atmospheric circulation model with sufficiently fine resolution. A more complete numerical description of the ocean including horizontal advection would allow a more detailed investigation of the oceanic part of polynya formation and maintenance.

Acknowledgments. The authors would like to thank W. Cohrs, H. Fischer, M. Harder, M. Kreyscher, and C. Lichey for preparing the sea ice model forcing fields. L. Sellmann provided the geostrophic and $10-\mathrm{m}$ wind data used to derive the empiric relation between geostrophic and surface winds. Atmospheric forcing data were derived from the ECMWF analyses that were received via the German Weather Service. This is AWI publication number 1445 .

\section{REFERENCES}

Andreas, E. L., C. A. Paulson, R. M. Williams, R. W. Lindsay, and J. A. Businger, 1979: The turbulent heat flux from Arctic leads. Bound.-Layer Meteor., 17, 57-91.

Carsey, F. D., 1980: Microwave observations of the Weddell polynya. Mon. Wea. Rev., 108, 2032-2044.

Fahrbach, E., G. Rohardt, N. Scheele, M. Schröder, V. Strass, and A. Wisotzki, 1995: Formation and discharge of deep and bottom water in the northwestern Weddell Sea. J. Mar. Res., 53, 515538.

Fischer, H., 1995: Vergleichende Untersuchungen eines optimierten dynamisch-thermodynamischen Meereismodells mit Beobach- tungen im Weddellmeer. Berichte zur Polarforschung, AlfredWegener-Institut, $130 \mathrm{pp}$.

Gordon, A. L., 1982: Weddell deep water variability. J. Mar. Res., 40, 199-217.

- , and B. A. Huber, 1984: Thermohaline stratification below the Southern Ocean sea ice. J. Geophys. Res., 89, 641-648.

Hibler, W. D., III., 1979: A dynamic thermodynamic sea ice model. J. Phys. Oceanogr., 9, 815-846.

Idso, S. B., and R. D. Jackson, 1969: Thermal radiation from the atmosphere. J. Geophys. Res. 74, 5379-5403.

Kottmeier, C., and H.-U. Stuckenberg, 1986: A quasi-geostrophic flow solution for the circulation over Antarctica. Beitr. Phys. Atmos., 59, 491-504.

_ , and H. H. Meyer, 1988: Ein einfaches analytisches Modell zur Darstellung der Zirkulation in Europa im Weichsel-Hochglazial, Erdkunde, Band 42 (4), 261-273.

- and D. Engelbart, 1992: Generation and atmospheric heat exchange of coastal polynyas in the Weddell Sea. Bound.-Layer Meteor., 60, 207-234.

, and L. Sellmann, 1996: Atmospheric and oceanic forcing of Weddell Sea ice motion. J. Geophys. Res., 101 (C9), 20 80920824.

— S. Ackley, E. Andreas, D. Crane, H. Hoeber, J. King, J. Launiainen, D. Limbert, D. Martinson, R. Roth, L. Sellmann, P. Wadhams, and T. Vihma, 1997: Wind and ice motion statistics in the Weddell Sea. World Meteorological Organisation, Technical Document, 1/1997.

Law, R., I. Simmonds, and W. F. Budd, 1992: Application of an atmospheric tracer model to high southern latitudes. Tellus, 44B, $358-370$.

Lemke, P., 1987: A coupled one-dimensional sea ice-ocean model. J. Geophys. Res., 92 (C12), 13 164-13 172.

— W. B. Owens, and W. D. Hibler III, 1990: A coupled sea icemixed layer-pycnocline model for the Weddel Sea. J. Geophys. Res., 95 (C6), 9513-9525.

Leppäranta, M., 1983: A growth model for black ice, snow ice, and snow thickness in subarctic basins. Nordic Hydrology, 14, 5970.

Martinson, D. G., P. D. Killworth, and A. L. Gordon, 1981: A convective model for the Weddell Polynya. J. Phys. Oceanogr., 11, 466-487.

Olbers, D., V. Gouretski, G. Seiss, and J. Schr'oter, 1992: Hydrographic Atlas of the Southern Ocean. Alfred-Wegener-Institut für Polar- und Meeresforschung, 82 plates.

Owens, W. B., and P. Lemke, 1990: Sensitivity studies with a sea ice-mixed layer-pycnocline model in the Weddell Sea. J. Geophys. Res., 95 (C6), 9527-9538.

Parkinson, C. L., and W. M. Washington, 1979: A large-scale numerical model of sea ice. J. Geophys. Res., 84 (C1), 311-337.

Rossow, W. B., and Coauthors, 1991: ISCCP Documentation of Cloud Data, WMO/TD-No. 266, 76 pp.

Semtner, A. J., Jr., 1976: A model for the thermodynamic growth of sea ice in numerical investigations of climate. J. Phys. Oceanogr., 6, 379-389.

Smith, R. B., 1979: The influence of mountains on the atmosphere. Advances in Geophysics, Vol. 21, Academic Press, 87-230.

Timmermann, R., 1997: Entstehung und Erhaltung einer Polynja im Weddellmeer, Berichte aus dem Fachbereich Physik, Rep. 77, Alfred-Wegener-Institut, Bremerhaven, 100 pp.

Zillman, J. W., 1972: A study of some aspects of the radiation and heat budgets of the southern hemisphere oceans. Meteorological Study, Vol. 26, Bureau of Meteorology, Dept. of the Interior, $526 \mathrm{pp}$.

Zwally, H. J., J. C. Comiso, and C. L. Parkinson, 1981: Satellitederived ice data sets. No. 1: Antarctic monthly average microwave brightness temperatures and sea ice concentrations 19731976. NASA Tech. Memo. 83812, 206 pp. 